\title{
Severity and location of lumbar spine stenosis affects the outcome of total knee arthroplasty
}

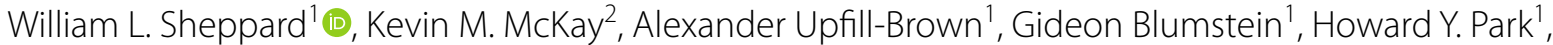
Akash Shah', Adam A. Sassoon ${ }^{1,2}$ and Don Y. Park ${ }^{1,2^{*}}$

\begin{abstract}
Background: Recent studies have noted that patients with pre-existing lumbar spinal stenosis (LSS) have lower functional outcomes after total knee arthroplasty (TKA). Given that LSS manifests heterogeneously in location and severity, its influence on knee replacement merits a radiographically targeted analysis. We hypothesize that patients with more severe LSS will have diminished knee mobility before and after TKA.
\end{abstract}

Methods: This retrospective case series assessed all TKAs performed at our institution for primary osteoarthritis from 2017-2020. Preoperative lumbar magnetic resonance image (MRI) with no prior lumbar spine surgery was necessary for inclusion. Stenosis severity was demonstrated by (1) anterior-posterior (AP) diameter of the thecal sac and (2) morphological grade. TKA outcomes in 103 cases (94 patients) were assessed by measuring preoperative and postoperative arc of motion (AOM), postoperative flexion contracture, and need for manipulation under anesthesia.

Results: Patients with mild stenosis did significantly better in terms of postoperative knee AOM. As AP diameter decreased at levels $L 1-2, L 2-3, L 3-4$, and $L 4-5$, there was a significant reduction in preoperative-AOM $(p<0.001$ for each), with a 16 degree decrease when using patients' most stenotic level $(p<0.001)$. The same was noted with respect to increased morphological grade $(p<0.001)$, with a 5 degree decrease for patients' most stenotic level $(p<0.001)$.

Conclusion: Severe LSS, which is readily demonstrated by a reduction in the AP diameter of the thecal sac or increased morphological grade on MRI, correlated with a significant reduction in preoperative AOM that was not improved after TKA. Persistent postoperative reductions in AOM may contribute to reduced patient satisfaction and recovery.

Level of evidence: Level 4

Keywords: Spinal stenosis, Total knee arthroplasty, Outcomes

*Correspondence: dypark@mednet.ucla.edu

1 Department of Orthopedic Surgery, University of California, Los Angeles, 1250 16th St Suite 2100, Santa Monica, CA 90404, USA

Full list of author information is available at the end of the article

\section{Background}

The relationships between the knee, hip, and spine have garnered interest, as pathology in one location often manifests over time as pain, deformity, or degeneration in another [1-5]. The rising incidence of knee and hip arthroplasty in an aging population [6] has provided an opportunity to further characterize these relationships and their effect on outcomes after surgical correction original author(s) and the source, provide a link to the Creative Commons licence, and indicate if changes were made. The images or other third party material in this article are included in the article's Creative Commons licence, unless indicated otherwise in a credit line to the material. If material is not included in the article's Creative Commons licence and your intended use is not permitted by statutory regulation or exceeds the permitted use, you will need to obtain permission directly from the copyright holder. To view a copy of this licence, visit http://creativecommons.org/licenses/by/4.0/. The Creative Commons Public Domain Dedication waiver (http://creativeco mmons.org/publicdomain/zero/1.0/) applies to the data made available in this article, unless otherwise stated in a credit line to the data. 
[7-10]. The prevalence of lumbar spinal stenosis (LSS) is higher in these populations as well; thus, there is an increased interest in how LSS affects total hip and knee arthroplasty outcomes when performed for primary osteoarthritis (OA) [8, 10-13].

Recent studies suggest that in patients undergoing total hip arthroplasty (THA), those with concomitant LSS appear to have worse functional outcomes, patient satisfaction scores, and activity levels when compared to patients without stenosis [11]. Additionally, there is evidence that in patients who undergo both THA and decompression for LSS, those who undergo lumbar decompression prior to THA have higher health-related quality of life (HRQOL) scores postoperatively [12]. Total knee arthroplasty (TKA) is also affected by prior diagnosis of LSS. Patients with stenosis who underwent TKA were found to have lower Knee Society postoperative functional outcome scores [13]. Prior TKA was also identified as an independent risk factor for poor outcomes 1 year after surgical decompression for LSS [9].

While the aforementioned studies elucidate a strong relationship between LSS and outcomes in lower extremity arthroplasty, they fail to explore whether the heterogeneity in severity and location of LSS differentially contributes to these poor reported results. Specifically, LSS can vary in morphology (central or lateral), present at any level of the lumbar spine, and differ in radiographic severity [14, 15]. Given this clinical variability, a more targeted examination may improve prognostic accuracy, allowing surgeons to better inform their patients' expectations preoperatively and to understand the potential consequences postoperatively $[16,17]$.

The purpose of this study was to expand upon potential relationships between lumbar stenosis and TKA, focusing on clinically relevant outcome measures such as Arc of Motion (AOM), Range of Motion (ROM), and need for Manipulations Under Anesthesia (MUA). We additionally sought to elucidate a potential relationship between the level of stenosis and the outcome measures listed above. We hypothesized that in patients undergoing TKA, decreases in both pre- and postoperative knee mobility would directly correlate with increasing severity and location of LSS.

\section{Methods}

\section{Study design}

After Institutional Review Board approval, all TKAs at a single healthcare system between 2017 and 2020 were identified. A total of 933 consecutive TKAs in 845 patients were performed for OA [3]. Of this cohort, we identified 103 TKAs performed in 94 patients who met the following inclusion criteria: pre-operative lumbar MRI, no prior history of lumbar spine surgery, pre- and post-operative knee mobility measurements, and at least 3 months of postoperative follow-up. Patients were excluded for not possessing preoperative lumbar spine MRI (706), prior lumbar spine surgery (57), inadequate follow-up with pre- and post-operative knee mobility measurements (30), and for the presence of severe scoliosis or suspected secondary OA based on chart review (37).

\section{Quantitative/qualitative grading of MRIs}

Measurements of LSS severity were performed on T2-weighted lumbar MRIs by 2 researchers independently. Severity was evaluated by (1) decreased AP diameter of the thecal sac $[16,18-20]$, demonstrated in Fig. 1A, B, and (2) increased morphological grade from L1-S1 as described by Guen et al. and demonstrated in Fig. 2A-D [17, 21]. Interrater reliability for (1) was assessed by calculating a correlation coefficient (0.96) and for (2) using Cohen's kappa coefficient (kappa $=0.82$, $p<0.05)[22]$.

\section{Demographics}

Patient demographics including age, sex, and body mass index (BMI) were noted. Potential preoperative confounders were also obtained for regression analyses, which included knee mobility, opiate use, and concurrent comorbidities (diabetes, hypertension, osteoporosis, osteopenia, and nicotine use). Presence or absence of symptomatic LSS was identified through retrospective chart review for documented history of unilateral or bilateral "sciatica", "back pain", and/or lower extremity "radiculopathy". Asymptomatic patients with a confirmed diagnosis of lumbar stenosis were also included in the analysis given the lack of defined correlation between imaging and symptom severity [23].

\section{TKA outcomes}

Primary TKA outcomes measured by attending surgeons, orthopedic residents, and physician assistants during pre- and post-operative office visits were gathered during retrospective chart review, including need for subsequent MUA, pre- and post-operative AOM (defined as the magnitude in degrees of knee flexion minus knee extension), presence of a flexion contracture, and the difference between pre-operative and post-operative AOM $(\triangle \mathrm{AOM})$. Measurements of continuous variables listed above represent active motion in that the subjects achieved these ranges without the assistance of the medical practitioners above. Discontinuous variables such as presence of flexion contracture or need for MUA were documented by medical practitioners accordingly. 


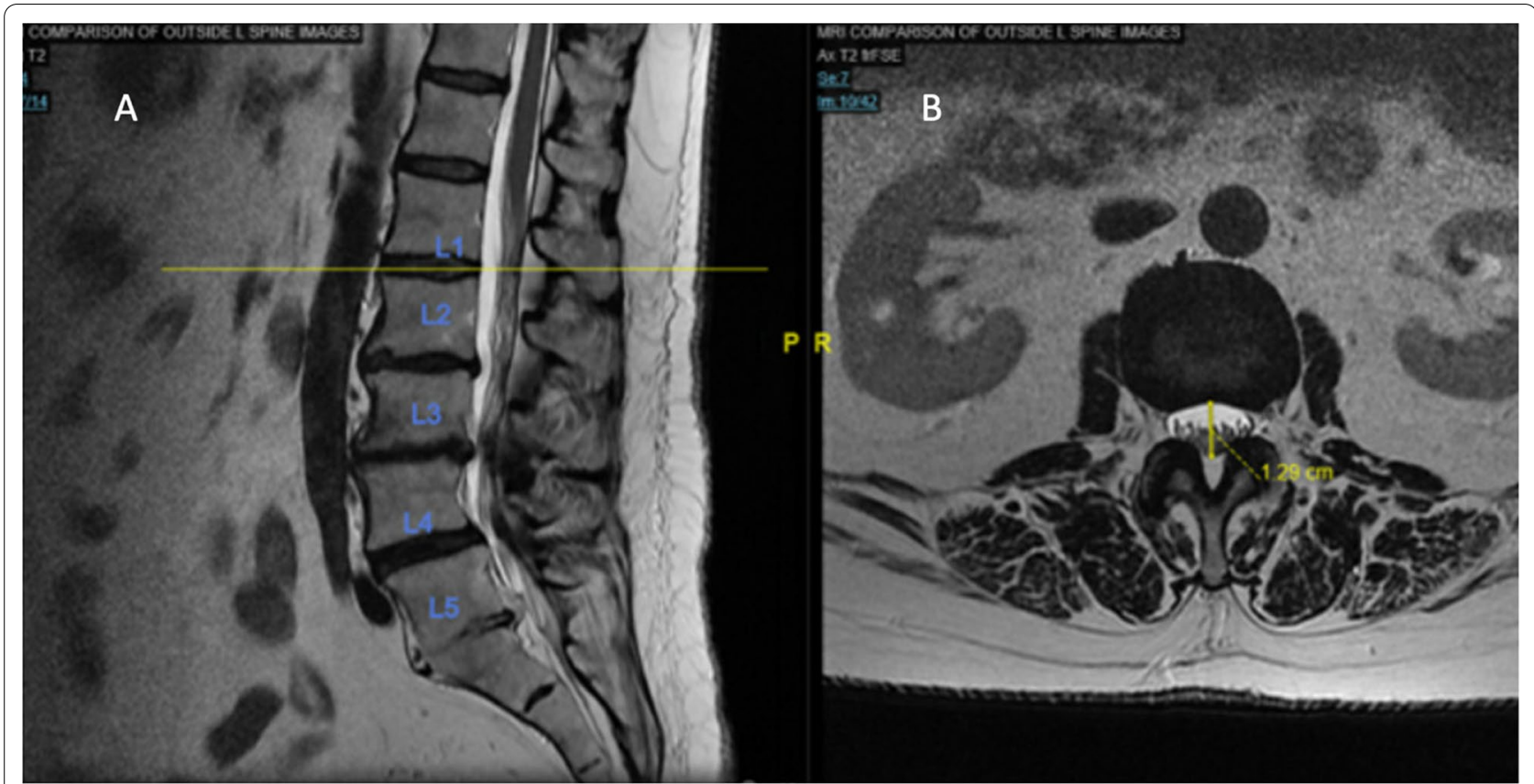

Fig. 1 Anterior-posterior (AP) diameter. A Sagittal T2-weighted MRI image at the intervertebral disc space between lumber level 1 and 2. B The corresponding T2-weighted axial MRI image from which the AP diameter measurement is shown. A line drawn from anterior-most aspect of the thecal sac to the most posterior aspect yields the measurement needed to assess stenosis in the AP plane

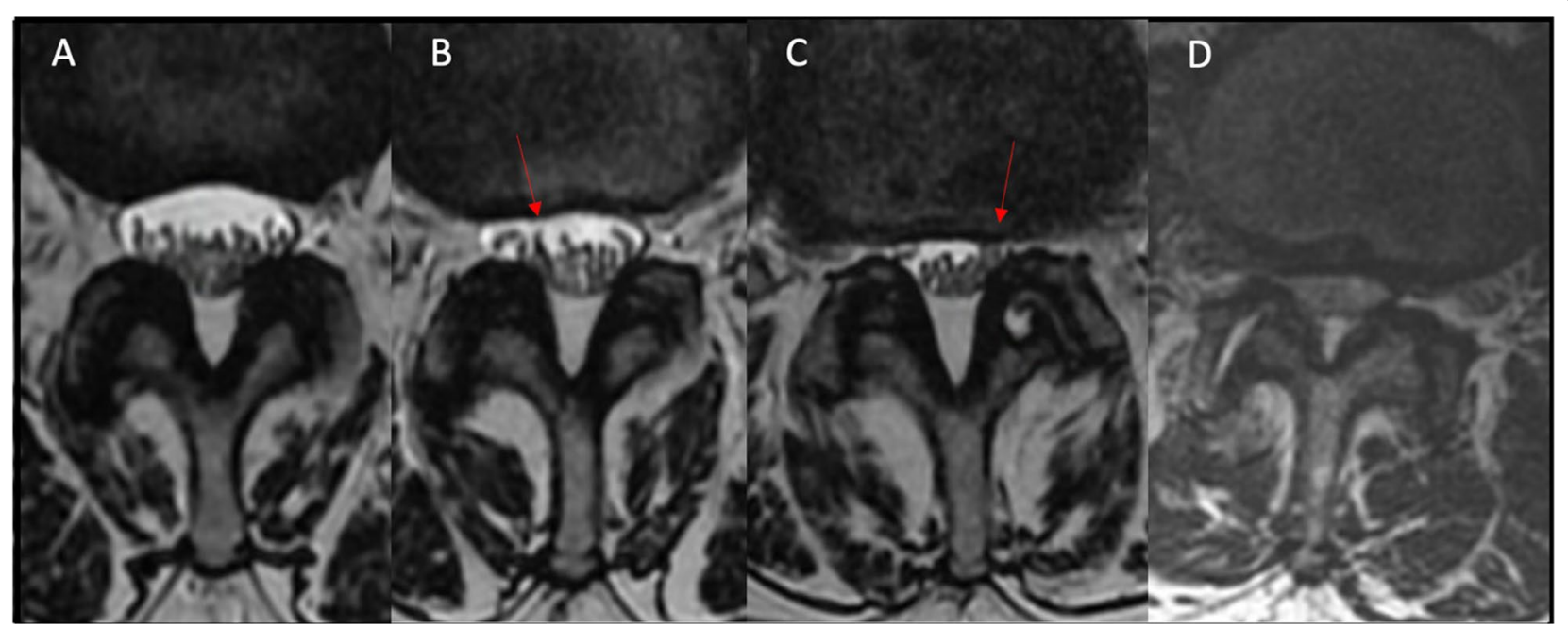

Fig. 2 Morphological grade of stenosis [17, 20]. Axial T2-weighted MRI images shown. A Grade 0, normal thecal sac without cerebral spinal fluid (CSF) effacement. B Grade 1, mild CSF effacement without significant nerve root crowding/compression. C Grade 2, moderate CSF effacement with nerve root crowding/compression. D Grade 3, severe CSF effacement with indistinguishable individual nerve roots due to significant crowding/ compression

\section{Statistical analysis}

Incidence of the aforementioned comorbidities was reported as averages with $95 \%$ confidence intervals $(\mathrm{CI})$. Multivariate regression was used to explore the functional relationship between AP diameter, morphological grade, and the outcomes of interest while controlling for confounding variables such as age, sex and BMI. Significance was determined as $p<0.05$. Analysis was conducted using $\mathrm{R}$ version 3.3.1. (R Core Team. R Foundation for Statistical Computing. Vienna, Austria). 
Table 1 Demographics and comorbidities

\begin{tabular}{lc}
\hline Demographics and comorbidities & \\
\hline Average age (years) & 71.3 \\
Male (\%) & 24.5 \\
Average BMI (kg/m²) & 30.7 \\
Diabetes mellitus (\%) & 22.3 \\
Hypertension (\%) & 72.3 \\
Osteoporosis/osteopenia (\%) & 21.2 \\
Current smoker (\%) & 4.3 \\
Preoperative opioid use (\%) & 38.3 \\
\hline
\end{tabular}

Table 2 Stenosis measured by AP diameter

\begin{tabular}{llll}
\hline Level & Mean $(\mathbf{c m})$ & SD $(\mathbf{c m})$ & $\mathbf{9 5 \% ~ C l ~}(\mathbf{c m})$ \\
\hline L1-2 & 1.43 & 0.25 & $1.39-1.48$ \\
L2-3 & 1.29 & 0.31 & $1.23-1.35$ \\
L3-4 & 1.12 & 0.32 & $1.04-1.17$ \\
L4-5 & 1.12 & 0.36 & $1.05-1.19$ \\
L5-S1 & 1.38 & 0.37 & $1.31-1.45$ \\
\hline
\end{tabular}

\section{Results}

\section{Demographics}

A total of 94 patients (103 operated upon knees) who underwent TKA for primary OA were included. Of these, the majority were female (73 females to 21 males), with an average BMI of 30.7, and mean age of 71.3 years. Regarding comorbidities, $22 \%$ of patients had diabetes mellitus, $73 \%$ had hypertension, $79 \%$ had osteopenia or osteoporosis, $4 \%$ were tobacco smokers, and $38 \%$ used opioids pre-operatively (Table 1). Average follow-up was 32 weeks (95\% CI 27-36 weeks). In total, 23 patients had history of bilateral sciatic and lower back pain, 54 had unilateral sciatic and lower back pain, 21 had isolated lower back pain, and 5 were asymptomatic.

\section{MRI measurements}

The average thecal sac AP diameter measured at intervertebral lumbar levels L1-2, L2-3, L3-4, L4-5, and L5-S1 is depicted in Table 2. The most stenotic levels in the AP plane were L3-4 and L4-5. Morphological grade was assessed at the same lumbar levels above. Table 3 depicts the number of subjects and the corresponding morphological grade at each level. The most stenotic levels were L2-3 and L3-4 on average. These levels accounted for $56.2 \%$ of morphological stenosis Grade 1 or more. The most stenotic level for both AP diameter and morphological grade overall was L3-4.
Table 3 Morphological grade of stenosis

\begin{tabular}{lcccc}
\hline Level & Grade $\mathbf{0}$ & Grade $\mathbf{1}$ & Grade 2 & Grade 3 \\
\hline $\mathrm{L} 1-2$ & 77 & 20 & 6 & 0 \\
$\mathrm{~L} 2-3$ & 64 & 26 & 12 & 1 \\
$\mathrm{~L} 3-4$ & 51 & 20 & 28 & 4 \\
$\mathrm{~L} 4-5$ & 59 & 21 & 19 & 4 \\
$\mathrm{~L} 5-\mathrm{S} 1$ & 102 & 1 & 0 & 0 \\
\hline
\end{tabular}

Table 4 Postoperative arc of motion vs AP diameter

\begin{tabular}{ll}
\hline Intervertebral level & $\begin{array}{l}\text { Regression } \\
\text { coefficient ( } p \\
\text { value) }\end{array}$ \\
\hline L1-2 & $5.21(0.32)$ \\
L2-3 & $3.22(0.45)$ \\
L3-4 & $7.67(0.055)$ \\
L4-5 & $3.75(0.27)$ \\
L5-S1 & $2.23(0.47)$ \\
Worst level of stenosis & $9.13(0.037)^{* *}$ \\
\hline
\end{tabular}

**Statistically significant

\section{TKA outcomes}

The mean preoperative AOM was 111.9 degrees (95\% CI 109.5-114.4), while the mean postoperative AOM was 117.5 (95\% CI 115.3-119.7). The mean $\triangle \mathrm{AOM}$ was $\sim 10.7$ degrees (95\% CI 8.41-13.0). A total of 9 (8.74\%) subjects required MUA, and 20 (19.42\%) knees had flexion contracture of at least 5 degrees from terminal extension. Patients with flexion contracture averaged 109.6 degrees of postoperative AOM (95\% CI 104.78-114.32). Patients underwent MUA within 90 days either for difficulty with achieving preoperative flexion (7 of 9 patients, $77.78 \%$ ), or difficult with both flexion and extension (2 of 9 patients, 22.23\%).

\section{Regression analysis}

Using the worst level of stenosis (classified by AP Diameter), linear models accounting for preoperative use of opioids, BMI, age, sex, presence of osteopenia, hypertension, or diabetes mellitus (DM) showed a slightly higher incidence of MUA in patients with worse AP diameter (OR 7.11, 95\% CI 1.03, 49.15, $p=0.045$ ), and a higher postoperative AOM if patients' worst level of stenosis was less severe (regression coefficient: 9.13, $p=0.037$; Table 4). Furthermore, a larger preoperative AOM was correlated with less AP stenosis at all levels except L5-S1. Similarly, with respect to preoperative AOM, there was strong correlation with less morphological grade stenosis at every intervertebral disc space except L5-S1 (Table 5). 
Table 5 Preoperative arc of motion vs AP diameter/ morphological grade

\begin{tabular}{lll}
\hline Intervertebral level & $\begin{array}{l}\text { AP diameter } \\
\text { regression coefficient } \\
\text { (p value) }\end{array}$ & $\begin{array}{l}\text { Morphological grade } \\
\text { regression coefficient } \\
\text { (p value) }\end{array}$ \\
\hline L1-2 & $17.64(<0.001)^{* *}$ & $7.18(<0.001)^{* *}$ \\
L2-3 & $13.57(<0.001)^{* *}$ & $6.76(<0.001)^{* *}$ \\
L3-4 & $12.37(0.001)^{* *}$ & $5.06(<0.001)^{* *}$ \\
L4-5 & $10.93(<0.001)^{* *}$ & $4.24(<0.001)^{* *}$ \\
L5-S1 & $4.47(0.15)$ & $4.67(0.70)$ \\
Worst level of stenosis & $15.76(<0.001)^{* *}$ & $5.20(<0.001)^{* *}$ \\
\hline
\end{tabular}

**Statistically significant

Specifically, there was a significant reduction in preoperative $\mathrm{AOM}(p<0.001$ for each), with a 16-degree decrease when using patients' most stenotic level measured by AP diameter $(p<0.001)$. The same was noted with respect to increased morphological grade $(p<0.001)$, with a 5 -degree decrease for the patients' most stenotic level $(p<0.001)$.

There were no significant relationships between the incidence of MUA or flexion contracture and grade of stenosis in linear models accounting for preoperative use of opioids, BMI, age, sex, presence of osteopenia, hypertension, and DM. There were also no significant relationships between postoperative AOM and morphological grade at any level. Using the worst level of stenosis (classified by morphological grade), when assessing $\triangle \mathrm{AOM}$, patients with higher morphological grades of stenosis counterintuitively had better postoperative $\triangle \mathrm{AOM}$ at L2-3 $(p=0.02)$, and a trend in the same direction at their worst level of stenosis $(p=0.06)$.

\section{Discussion}

This case series demonstrates a correlation between severity of lumbar spine stenosis and knee mobility/ function in a group of patients who subsequently underwent total knee arthroplasty for primary osteoarthritis. In elucidating this relationship, it gives credence to the variability of spinal stenosis by utilizing radiographic measures to stratify LSS in severity and location (specific lumbar intervertebral disc space), providing a more targeted analysis.

For both measures of stenosis severity, namely (1) increasing morphological grade and (2) decreasing AP diameter, patients demonstrated reduced preoperative AOM when stenosis was noted at any level of the lumbar spine aside from L5-S1. This relationship was inversely proportional. As the morphological grade of stenosis increased (worsened) or AP diameter of the thecal sac lessened, a correlation was noted with reductions in preoperative AOM at all levels except L5-S1. This previously undocumented relationship between stenosis severity and poor preoperative knee mobility was most significant when assessing each patient's worst/most stenotic level (Table 5), further supporting our hypothesis that this deficit was related to LSS. At the worst level of stenosis (most often L3-4), 16- and 5-degree reductions in preoperative AOM were noted when assessed by AP diameter and morphological grade, respectively $(p<0.001)$. At L5-S1, our series revealed a lack of stenosis by both utilized measures, which can be explained by increased anatomical size of the spinal canal at this level on average, and less nerve rootlets within the thecal sac $[17,20]$.

Reduced preoperative knee mobility has previously been shown to be associated with decreased functional outcomes following TKA [24]. However, there are limited data on the effect of optimizing preoperative knee mobility in the sagittal plane prior to TKA [25]. This study supports the importance of evaluating patients for the presence of factors (including LSS) that may contribute to decreased preoperative AOM. In this series, patients did not improve significantly from the preoperative $\mathrm{AOM}$ assessment, regaining approximately 10 degrees on average postoperatively. This result emphasizes that determining the etiology of poor preoperative AOM is paramount, as these deficits may not be correctable by TKA alone.

Additionally, postoperative AOM was significantly reduced at the level of most significant stenosis in the AP plane (Table 4), which was located at either L2-3 or L3-4 in nearly $60 \%$ of subjects overall. These levels contribute most significantly to quadricep functionality when the L3 nerve root is affected, which could explain the increased incidence of postoperative MUA when these levels are affected. Furthermore, in a seemingly counterintuitive manner, patients with worse grade of stenosis at L2-3 had better recovery of knee mobility following TKA. Stenosis at this level may have had less effect on the L3 nerve root, allowing for better postoperative rehabilitation of the quadriceps.

While prior work in this area is limited, there are important comparisons to be made with our study that may guide future investigations. Additionally, several studies have noted similar correlations between TKA and lumbar stenosis to a lesser extent. Pivec et al. investigated outcomes of TKA (Knee Society objective scores, function scores, range of motion, radiographic outcomes, and implant survivorship) in 115 patients with LSS, finding significantly lower mean postoperative Knee Society function and objective scores compared to control patients without stenosis [13]. However, they neither found postoperative differences in knee range of motion 
between study groups, nor preoperative difference between LSS and non-LSS cohorts. This incongruity may be attributed to differences in selection criteria used for their study, which required patients in the LSS cohort to have an official diagnosis of LSS or prior surgery for LSS, possibly enhancing preoperative knee range of motion [13]. Our study excluded patients with prior surgery for LSS for several reasons. Corrective surgery for lumbar degenerative disease (LDD) has been shown to increase failure rates in TKA above that observed in patients with LDD alone [8]. Further, our study relies on preoperative MRI analysis as we attempted to negate postoperative MRI degradation as well as occult postoperative epidural scarring that could confound our findings [26]. This approach allows for a more nuanced investigation of the isolated effect of LSS on knee mobility surrounding TKA.

There are several limitations to this study which include the following. (1) The retrospective design of this study, which relies on chart review for collection of data on patient symptoms. (2) The methods by which we define stenosis are based on several articles [16-20]. While our observers achieved acceptable interrater reliability coefficients, providing confidence in the MRI measurements, these methods lack normalization to take into account variations in normal subject anatomy. While there are several studies offering additional methodologies for radiographic grading of LSS [15, 17, 27-29] and attempting to define population parameters [21], there is a lack of consensus regarding MRI measurements and their true significance as prognostic indicators $[16,23$, 30-32]. Regarding the particular methodology we utilized in grading LSS, the authors found some deficiencies in its use. Namely, some patients have mild decrease in anterior CSF space (very little to no obliteration), but do have some clumping of the cauda equina, making it difficult to distinguish grades 1 and 2 as currently defined by Guen, Y. L. et al. [17]. (3) There is a lack of patient reported outcome scores to correlate with the functional outcomes stated above. This is another inherent limitation of the retrospective nature of this study as $>80 \%$ of subjects lacked patient reported outcome scores. The effect of patient-reported LSS symptom severity scores on TKA outcomes is an important future direction. Lastly, some heterogeneity in MRI quality and formatting of axial slices exists due to studies obtained at outside facilities. However, despite these limitations, we believe this study successfully identifies several novel relationships between lumbar stenosis and its effect on TKA functional outcomes through reductions in pre- and postoperative $\mathrm{AOM}$, most influenced by stenosis at levels between L2-L4.

In conclusion, this study supports the evaluation of patients prior to TKA for any signs/symptoms of LSS.
Patients with preoperative LSS, especially at levels affecting the L3 nerve root, may have poor pre- and postoperative knee $\mathrm{AOM}$ and are at risk for reduced patient satisfaction, function, and overall recovery after TKA. While preoperative AOM was most significantly reduced by concomitant LSS at various levels in our series, these reductions did not improve significantly following TKA, with 9 subjects requiring MUA and 20 subjects developing flexion contracture postoperatively. These findings suggest that a preoperative lumbar spine evaluation may be useful in properly selecting patients who will be candidates for optimal recovery of knee functionality after TKA, as well as adequately discussing expectations and goals with patients before surgery.

\section{Abbreviations}

LSS: Lumbar spinal stenosis; TKA: Total knee arthroplasty; MRI: Magnetic resonance imaging; AP: Anterior-posterior; AOM: Arc of motion; THA: Total hip arthroplasty; HRQOL: Health-related quality of life; OA: Osteoarthritis; BMI: Body mass index; MUA: Manipulation under anesthesia; $\triangle \mathrm{AOM}$ : Difference between preoperative and postoperative AOM; DM: Diabetes mellitus; CSF: Cerebrospinal fluid.

\section{Acknowledgements}

Not applicable.

\section{Authors' contributions}

DYP, WLS, and AAS contributed to conceptualization; KMM and WLS provided methodology; WLS provided software; WLS, KMM, and AUB performed validation; WLS, AS, and AUB done formal Analysis; DYP performed investigation, supervision, and project administration; DYP and AAS provided resources; KMM, GB, AS, and WLS performed data curation; HYP, KMM, and WLS performed writing — original draft preparation; WLS, DYP, GB, HYP, and KMM performed writing - review and editing; DYP and AAS contributed to visualization; Funding acquisition is not applicable. All authors read and approved the final manuscript.

\section{Funding}

The authors certify that he or she has no commercial associations (e.g., consultancies, stock ownership, equity interest, patent/licensing arrangements, etc.) that might pose a conflict of interest in connection with the submitted article. Additionally, there are no funding sources to report for this study.

\section{Availability of data and materials}

The datasets generated and/or analyzed during the current study are not publicly available due to the regulations by our Institutional Review Board, but can be made available from the corresponding author by request.

\section{Declarations}

\section{Ethics approval and consent to participate}

This study was conducted in accordance with the University of California Los Angeles' clinical research guidelines and with approval from the institutional review board (IRB) of UCLA Health Systems.

\section{Consent for publication}

Not applicable.

\section{Competing interests}

The authors declare that they have no competing interests.

\section{Author details}

${ }^{1}$ Department of Orthopedic Surgery, University of California, Los Angeles, 125016 th St Suite 2100, Santa Monica, CA 90404, USA. ${ }^{2}$ David Geffen School 
of Medicine, University of California, Los Angeles, 10833 Le Conte Ave, Los Angeles, CA 90095, USA.

Received: 26 August 2021 Accepted: 2 December 2021

Published online: 20 December 2021

\section{References}

1. Oshima Y, Watanabe N, lizawa N, Majima T, Kawata M, Takai S. Knee-hipspine syndrome: improvement in preoperative abnormal posture following total knee arthroplasty. Adv Orthop. 2019. https://doi.org/10.1155/ 2019/8484938.

2. Boyle JK, Anthony IC, Jones BG, Wheelwright EF, Blyth MJ. Influence of low back pain on total knee arthroplasty outcome. Knee. 2014;21(2):4104. https://doi.org/10.1016/j.knee.2013.12.003.

3. Sheppard WL, Upfill-Brown A, McKay KM, Park HY, Shah A, Park DY, Sassoon AA. Lumbar spine sagittal mismatch deformity negatively affects total knee arthroplasty outcomes. J Knee Surg. 2021. https://doi.org/10. 1055/s-0041-1723979.

4. Clement ND, MacDonald D, Simpson AH, Burnett R. Total knee replacement in patients with concomitant back pain results in a worse functional outcome and a lower rate of satisfaction. Bone Joint J. 2013;95B(12):1632-9. https://doi.org/10.1302/0301-620X.95B12.31684.

5. Collados-Maestre I, Lizaur-Utrilla A, Martinez-Mendez D, Marco-Gomez L, Lopez-Prats FA. Concomitant low back pain impairs outcomes after primary total knee arthroplasty in patients over 65 years: a prospective, matched cohort study. Arch Orthop Trauma Surg. 2016;136(12):1767-71. https://doi.org/10.1007/s00402-016-2576-8.

6. Maradit Kremers H, Larson DR, Crowson CS, et al. Prevalence of total hip and knee replacement in the United States. J Bone Joint Surg Am. 2015;97(17):1386-97. https://doi.org/10.2106/JBJS.N.01141.

7. Ozaki M, Fujita N, Miyamoto A, Suzuki S, Tsuji O, Nagoshi N, Okada E, Yagi M, Tsuji T, Nakamura M, Matsumoto M. Impact of knee osteoarthritis on surgical outcomes of lumbar spinal canal stenosis. J Neurosurg Spine. 2019. https://doi.org/10.3171/2019.10.spine19886.

8. Malahias M-A, Gu A, Richardson SS, De Martino I, Mayman DJ, Sculco TP, Sculco PK. Association of lumbar degenerative disease and revision rate following total knee arthroplasty. J Knee Surg. 2020. https://doi.org/10. 1055/s-0040-1701651.

9. Ho Lee B, Kim T-H, Chong H-S, Lee S-H, Park J-O, Kim H-S, Shim DW, Lee HM, Moon S-H. Prognostic factors for surgical outcomes including preoperative total knee replacement and knee osteoarthritis status in female patients with lumbar spinal stenosis. J Spinal Disord Tech. 2015;28(2):4752. https://doi.org/10.1097/BSD.0b013e31828d003d.

10. Goodman SB, Lachiewicz PF, Liu N, Wood KB. Knee or spine surgery first? A survey of treatment order for patients with concurrent degenerative knee and lumbar spinal disorders. J Arthroplasty. 2020. https://doi.org/10. 1016/j.arth.2020.03.018.

11. Jauregui JJ, Banerjee S, Issa K, Cherian JJ, Mont MA. Does co-existing lumbar spinal canal stenosis impair functional outcomes and activity levels after primary total hip arthroplasty? J Arthroplasty. 2015;30(9):1569-73. https://doi.org/10.1016/j.arth.2015.03.017.

12. Eneqvist T, Bülow $E$, Nemes $S$, Brisby H, Fritzell P, Rolfson O. Does the order of total hip replacement and lumbar spinal stenosis surgery influence patient-reported outcomes: an observational register study. J Orthop Res. 2020. https://doi.org/10.1002/jor.24813.

13. Pivec R, Johnson AJ, Naziri Q, Issa K, Mont MA, Bonutti PM. Lumbar spinal stenosis impairs function following total knee arthroplasty. J Knee Surg. 2012;26(1):59-64. https://doi.org/10.1055/s-0032-1313754.

14. Lee SY, Kim TH, Oh JK, Lee SJ, Park MS. Lumbar stenosis: a recent update by review of literature. Asian Spine J. 2015. https://doi.org/10.4184/asj. 2015.9.5.818.

15. Schizas C, Theumann N, Burn A, Tansey R, Wardlaw D, Smith FW, Kulik G. Qualitative grading of severity of lumbar spinal stenosis based on the morphology of the dural sac on magnetic resonance images. Spine. 2010;35(21):1919-24. https://doi.org/10.1097/BRS.0b013e3181d359bd.

16. Steurer J, Roner S, Gnannt R, Hodler J; LumbSten Research Collaboration. Quantitative radiologic criteria for the diagnosis of lumbar spinal stenosis: a systematic literature review. BMC Musculoskelet Disord. 2011;12:175. https://doi.org/10.1186/1471-2474-12-175.
17. Guen YL, Joon WL, Hee SC, Kyoung-Jin O, Heung SK. A new grading system of lumbar central canal stenosis on MRI: an easy and reliable method. Skeletal Radiol. 2011;40(8):1033-9. https://doi.org/10.1007/ s00256-011-1102-x.

18. Jönsson B, Annertz M, Sjöberg C, Strömqvist B. A prospective and consecutive study of surgically treated lumbar spinal stenosis. Part I: clinical features related to radiographic findings. Spine (Phila Pa 1976). 1997;22(24):2932-7. https://doi.org/10.1097/00007632-199712150-00016.

19. Kalichman L, Cole R, Kim DH, et al. Spinal stenosis prevalence and association with symptoms: the Framingham Study. Spine J. 2009;9(7):545-50. https://doi.org/10.1016/j.spinee.2009.03.005.

20. Hughes A, Makirov SK, Osadchiy V. Measuring spinal canal size in lumbar spinal stenosis: description of method and preliminary results. Int J Spine Surg. 2015. https://doi.org/10.14444/2008.

21. Mamisch N, Brumann M, Hodler J, Held U, Brunner F, Steurer J. Radiologic criteria for the diagnosis of spinal stenosis: results of a delphi survey. Radiology. 2012;264(1):174-9. https://doi.org/10.1148/radiol.12111930.

22. McHugh ML. Interrater reliability: the kappa statistic. Biochem Med. 2012;22(3):276-82. https://doi.org/10.11613/bm.2012.031.

23. Genevay S, Atlas SJ. Lumbar spinal stenosis. Best Pract Res Clin Rheumatol. 2010;24(2):253-65. https://doi.org/10.1016/j.berh.2009.11.001.

24. Shi MG, Lü HS, Guan ZP. Zhonghua Wai Ke Za Zhi. 2006:44(16):1101-5.

25. Rodríguez-Merchán EC. The stiff total knee arthroplasty: causes, treatment modalities and results. EFORT Open Rev. 2019;4(10):602-10. https:// doi.org/10.1302/2058-5241.4.180105.

26. Malhotra A, Kalra VB, Wu X, Grant R, Bronen RA, Abbed KM. Imaging of lumbar spinal surgery complications. Insights Imaging. 2015. https://doi. org/10.1007/s13244-015-0435-8.

27. Lee S, Lee JW, Yeom JS, et al. A practical MRI grading system for lumbar foraminal stenosis. AJR Am J Roentgenol. 2010;194(4):1095-8.

28. Ishimoto $Y$, Jamaludin $A$, Cooper $C$, et al. Could automated machinelearned MRI grading aid epidemiological studies of lumbar spinal stenosis? Validation within the Wakayama spine study. BMC Musculoskelet Disord. 2020;21(1):158. https://doi.org/10.1186/s12891-020-3164-1.

29. Pierro A, Cilla S, Maselli G, Cucci E, Ciuffreda M, Sallustio G. Sagittal normal limits of lumbosacral spine in a large adult population: a quantitative magnetic resonance imaging analysis. J Clin Imaging Sci. 2017;7:35. https://doi.org/10.4103/jcis.JCIS_24_17.

30. Beattie PF, Meyers SP, Stratford P, Millard RW, Hollenberg GM. Associations between patient report of symptoms and anatomic impairment visible on lumbar magnetic resonance imaging. Spine (Phila Pa 1976). 2000;25(7):819-28. https://doi.org/10.1097/00007632-200004010-00010.

31. Andreisek G, Hodler J, Steurer J. Uncertainties in the diagnosis of lumbar spinal stenosis. Radiology. 2011;261(3):681-4. https://doi.org/10.1148/ radiol.11111086.

32. Jain N, Acharya S, Adsul NM, Haritwal MK, Kumar M, Chahal RS, Kalra KL. Lumbar canal stenosis: a prospective clinicoradiologic analysis. J Neurol Surg Part A Cent Eur Neurosurg. 2020. https://doi.org/10.1055/s-00391698393.

\section{Publisher's Note}

Springer Nature remains neutral with regard to jurisdictional claims in published maps and institutional affiliations.

Ready to submit your research? Choose BMC and benefit from:

- fast, convenient online submission

- thorough peer review by experienced researchers in your field

- rapid publication on acceptance

- support for research data, including large and complex data types

- gold Open Access which fosters wider collaboration and increased citations

- maximum visibility for your research: over 100M website views per year

At BMC, research is always in progress.

Learn more biomedcentral.com/submissions 